\title{
OS EUA E O “GOLPE LEGAL" NA VENEZUELA
}

\author{
THE USA AND THE “LEGAL COUP” IN VENEZUELA
}

Resumo: O presente texto tem o objetivo de analisar, a ação dos EUA na Venezuela visando a desestabilização do governo Hugo Chávez. Para tal, utilizamos como fonte de analise o documento intitulado USAID/OIT PROGRAMMATIC SUPPORT FOR COUNTRY TEAM 5 POINTS STRATEGY, disponibilizado no site Wikileaks, que demonstra os planos estadunidenses para enfraquecer a base de apoio do governo democraticamente eleito de Hugo Chávez na Venezuela.

Palavras-chave: Venezuela; Hugo Chávez; Wikileaks

Abstract: This article has the aim of analyzing how the USA acted in Venezuela in order to destabilize the Hugo Chávez's government. To fulfill this goal, we used the document named USAID/OIT PROGRAMMATIC SUPPORT FOR COUNTRY TEAM 5 POINTS STRATEGY, available on the Wikileaks website. This document shows the Americans' plans to weaken the supporters of the democratic elective government of Hugo Chávez in Venezuela.

Keywords: Venezuela; Hugo Chávez; Wikileaks.

\section{Introdução}

O ano de 2006 foi intenso na Venezuela. Desde a eleição de Hugo Chávez para presidente da República, em 2002, o país enfrentava uma grave crise política que, em última instância, resultou em confrontos armados pelas ruas das grandes cidades do país, em especial Caracas, e em um fracassado golpe de Estado, ainda em 2002. A disputa pelo poder político no país desnudou a luta de classes na Venezuela, sendo que a elite oligárquica que monopolizava o poder do Estado desde $1958^{1}$ e que havia quebrado a

\footnotetext{
* Tiago Santos Salgado: graduado em História pela UNESP, Mestre em História pela PUC-SP e doutorando em História pela PUC-SP. Membro do Centro de Estudos de História da América Latina (Cehal-PUC-SP). E-mail para contato: tiago_salgado1986@hotmail.com

${ }^{1}$ O período entre 1958-1998 é conhecido como Pacto do Punto Fijo e pode ser considerado como uma proposta de costurar um acordo para reduzir as diferenças ideológicas e pragmáticas entre os principais
} 
economia do país com uma política neoliberal, não aceitava que um ex-militar, ligado às classes populares chegasse à presidência.

Após eleito, Chávez buscou reformar o sistema político venezuelano, aumentando a ingerência do Estado no principal setor da economia, o petroleiro. Dessa forma, ampliou os canais de representação democrática, colocou em prática uma série de programas sociais, com o intuito de melhorar serviços básicos como saúde e educação, e diversificou as relações internacionais do país, estreitando as relações entre as nações latino-americanas, como Cuba.

Diante desse cenário, o governo chavista foi alvo de intensa oposição por parte da oligarquia política, que se autointitula a "sociedade civil organizada", sendo composta pelos partidos políticos "tradicionais", Acción Democrática $(A D)$ e Copei, dos meios de comunicação, de parte da classe média e da central patronal Fedecameras; esses grupos tinham como objetivo, mesmo com os avanços sociais atingidos no período, interromper o governo democraticamente eleito de Chávez.

Segundo dados oficiais, divulgados pelo Instituto Nacional de Estadística da Venezuela, após as Missões ${ }^{2}$, o número de lares que estavam na linha de pobreza caiu de $54 \%$ em 2003 para $26,8 \%$ em 2010, e para os lares em pobreza extrema caiu de $25,1 \%$ em 2003 para $7 \%$ em 2007 (INSTITUTO NACIONAL DE ESTADÍSTICA apud SEABRA, 2012, p. 151).

partidos políticos e arquitetar, assim, uma conciliação de classe para que a democracia fosse instaurada na Venezuela. Ver: COLMENARES, Elio. La inssurección de febrero. Una análisis para la lucha revolucionaria. Caracas, Ediciones La Chipa, 1989.

2 "Missões" são ações cívico-militares que têm como objetivo levar educação, saúde e alimentos, entre outros recursos, para regiões periféricas das grandes cidades venezuelanas. Uma das "missões" mais conhecidas é a "Missão Robinson", que tem como objetivo diminuir as taxas de analfabetismo no país. Outro exemplo é a missão "Bairro Adentro" que se caracteriza por levar médicos cubanos aos bairros mais pobres de Caracas. Em troca desse serviço, a Venezuela vende petróleo subsidiado à ilha de Fidel. Chávez também coloca em prática os chamados "Círculos Bolivarianos", que se caracterizam por serem grupos organizados de sete a onze pessoas que se reúnem para discutir os problemas da própria comunidade, canalizá-los para o organismo competente e buscar soluções. Funcionam à maneira de assembleias populares em que se discutem, sobretudo, matérias de interesse local, problemas do dia-a-dia e a prestação de serviços comunitários. O presidente Hugo Chávez concebeu os "círculos bolivarianos" para dar maior alcance à sua Revolução, criando agentes de difusão do pensamento bolivariano. 
Assim, as tentativas começaram em 2002, com o golpe militar que durou 48 horas, e perderam força ${ }^{3}$ em 2006, quando Chávez venceu novamente a eleição presidencial. Entre esses dois acontecimentos, no entanto, a oposição organizou uma greve geral da indústria petroleira em 2002, um boicote às eleições legislativas de 2005 e convocou um referendo revocatório contra Chávez em 2004, sendo que em todas as ocasiões a oposição foi derrotada pelas forças governistas, compostas em grande parte de setores das classes populares venezuelanas. Dessa forma, o ano de 2006 representou, ao mesmo tempo, o fortalecimento do governo e o enfraquecimento da oposição.

Portanto, é nesse contexto que, em novembro de 2006, o então embaixador estadunidense na Venezuela, William Browmfield, envia ${ }^{4}$ para a representação estadunidense em vários países ${ }^{5}$, entre eles Brasil, Cuba e Vaticano, o documento intitulado USAID/OIT PROGRAMMATIC SUPPORT FOR COUNTRY TEAM 5 POINTS STRATEGY, cuja a intenção é explicar as cinco estratégias formuladas por Washington, e colocadas em prática entre os anos de 2004 e 2006, para desestabilizar o governo Chávez e, em especial, interferir no resultado das eleições presidenciais de 2006, uma vez que, segundo o documento:

During his 8 years in power, President Chavez has systematically dismantled the institutions of democracy and governance. The USAID/OTI program objectives in Venezuela focus on strengthening democratic institutions and spaces through non-partisan cooperation with many sectors of Venezuelan society. ${ }^{6}$

O documento demonstra como as políticas colocadas em práticas durante o governo Chávez desagradaram o EUA, que tentaram desestabilizar o governo venezuelano, sendo uma importante ferramenta para se entender como os EUA

\footnotetext{
${ }^{3}$ Mesmo com o fortalecimento das forças governistas e com o enfraquecimento da oposição, as ações para desestabilizar o governo bolivariano aumentaram após a morte de Chávez em 2013, com a intensificação de mobilizações populares.

4 Tal documento, intitulado "USAID/OIT PROGRAMMATIC SUPPORT FOR COUNTRY TEAM 5 POINTS STRATEGY" data de nove de novembro de 2006 e é classificado como Secreto pelo Departamento de Estado dos EUA, sendo que faz parte de uma série de documentos vazados pelo exfuncionário da CIA, Edward Snowden e publicados no site Wickileaks.

${ }^{5}$ Os países que receberam o documento foram: Bolívia, Brasil, Canadá, Colômbia, Cuba, Equador, México, Holanda, Nicarágua, Peru e Vaticano, além do Conselho de Segurança Nacional, a Missão dos EUA na União Europeia, Nações Unidas e o United States Southern Command.

${ }^{66}$ Disponível em: https://search.wikileaks.org/plusd/cables/06CARACAS3356_a.html
} 
auxiliaram a oposição venezuelana a retomar o controle do Estado do país. Dessa forma, para a análise da fonte em questão, se objetiva entender o sentido presente na particularidade do próprio discurso, ou seja, entender como, a partir de categorias historicamente construídas uma dada concretude social é naturalizada por meio de uma construção discursiva ideológica, no caso, do documento vinculado à embaixada dos EUA - sendo que entendemos ideologia como "toda produção espiritual que, independentemente de sua verdade (isto é, de sua maior ou menor adequação ao real), cumpre uma função social de elaborar no plano ideal a realidade, a fim de conscientizar e operacionalizar a prática humana" (COTRIM, 1999, p. 17). Assim, buscaremos entender a intencionalidade do discurso estadunidense em relação à Venezuela a partir do documento assinado pelo então embaixador.

\section{A relação entre os EUA e a Venezuela}

A ingerência dos EUA na Venezuela é de longa data. Como petróleo venezuelano é a principal fonte desse produto para o mercado estadunidense, os EUA acompanham de perto os passos do governo chavista desde a eleição em 1998, sendo que apoiou publicamente o golpe de Estado em 2002. O estranhamento entre os dois países teve início no ano de 2001, quando Chávez assinou a Lei de Hidrocaburetos, com a postura crítica da Venezuela em relação ao comportamento dos EUA na guerra contra o Afeganistão e o Iraque, e se radicalizou depois do histórico discurso de Chávez na $\mathrm{ONU}^{7}$, quando este atacou o então presidente George W. Bush. Com a aproximação venezuelana com Cuba e com países como Rússia e Irã, a relação se deteriorou ainda mais.

Assim, a relação da Venezuela com os Estados Unidos era alvo de grande polêmica, já que, apesar da intensa troca comercial entre os dois países, o discurso adotado por Chávez era declaradamente antiamericano. Da mesma forma, mesmo sendo um histórico parceiro comercial da Venezuela, o governo estadunidense se colocou de

\footnotetext{
${ }^{7}$ Em 2006, durante sua fala na ONU, Chávez disse: “"O diabo veio aqui ontem. Ainda cheira a enxofre hoje", referindo-se ao pronunciamento do então presidente dos EUA George W. Bush no dia anterior.
} 
forma contrária à eleição de Chávez, sendo acusado de financiar ações oposicionistas, fato que se confirma com a análise do documento.

Em grande parte, a oposição dos Estados Unidos se deu em decorrência da aprovação da Lei de Hidrocarburetos - que aumentava a participação do Estado venezuelano nos lucros do petróleo - e da reativação, promovida por Chávez, da Organização dos Países Exportadores de Petróleo durante a II Cúpula de Chefes de Estado da OPEP, ocorrida em setembro de 2000, ocasião em que o então presidente venezuelano promoveu a valorização dos preços do petróleo no mercado internacional, dando novo ânimo à Organização, que:

[...] havia se convertido numa sombra do que havia sido antes; os países membros regularmente ignoravam ou evadiam as cotas impostas pela organização. Venezuela em particular havia se convertido num dos países membros menos obedientes à organização. (WILPERT apud SEABRA, 2012, p. 126).

O interesse dos EUA na Venezuela, portanto, é inegável. Como o país norteamericano é uma superpotência militar, a necessidade de combustíveis é imensa e a Venezuela é um país com uma das maiores reservas de petróleo do mundo, com acesso fácil e rápido - via oceano - para o mercado dos Estados Unidos. Também é importante lembrar que a indústria petroleira demanda um largo investimento em infraestrutura e tecnologia, fato que estimulou a presença de empresas de capital estadunidenses no território venezuelano desde as primeiras décadas do século XX (OLIVEIRA, 2011, p. 124). Portanto, a razão da oposição dos Estados Unidos à política posta em prática pelo governo Chávez se relaciona com o fato de que seus interesses econômicos e estratégicos foram prejudicados pelas medidas adotadas pelo governo venezuelano em relação à venda de petróleo.

\section{Os EUA e o governo Chávez}

Tendo em mente a definição proposta de ideologia, é possível perceber que, mesmo com a intenção de deixar claro o caráter "non-partisan" do governo dos EUA em 
relação à Venezuela, a análise do discurso e de seu conteúdo intrínseco, bem como a comparação de tal discurso com a realidade social venezuelana, nos permite afirmar que o documento retrata claramente como os EUA trabalharam, juntamente com a oposição venezuelana, para desestabilizar o governo de Chávez por meio da ação do Escritório de Alternativas de Transição, vinculado à Agência dos Estados Unidos para Desenvolvimento Internacional, USAID/OIT ${ }^{8}$, que, entre os anos de 2004 e 2006, buscou, segundo o próprio documento, "fortalecer instituições democráticas; penetrar na base de apoio chavista; dividir o chavismo; proteger os interesses econômicos vitais dos EUA e isolar internacionalmente Chávez.”. Esses cinco pontos, foram os norteadores do discurso da oposição venezuelana contra Chávez, que também é considerada pelos EUA como a "sociedade civil organizada".

Organized civil society is an increasingly important pillar of democracy, one where President Chavez has not yet been able to assert full control. 5. (S) OTI has supported over 300 Venezuelan civil society organizations with technical assistance, capacity building, connecting them with each other and international movements, and with financial support upwards of $\$ 15$ million. Of these, 39 organizations focused on advocacy have been formed since the arrival of OTI; many of these organizations as a direct result of OTI programs and funding. ${ }^{9}$

Como é possível perceber, de acordo com o documento, a ação dos EUA na Venezuela visava defender e fortalecer instituições democráticas e mobilizar a sociedade civil, algo que, segundo o embaixador estadunidense, Chávez não foi capaz de realizar. Cotejando as abstrações realizadas pelo discurso presente no documento com os dados da realidade concreta venezuelana no período, é possível identificar o descompasso entre a assertiva estadunidense e a realidade social do país.

\footnotetext{
${ }^{8}$ Segundo Eva Golinger: "La USAID funciona para promover a los intereses económicos y estratégicos de Estados Unidos en casi todo el planeta. Sus departamentos dedicados a transición, reconstrucción, gerencia de conflictos, desarrollo económico, gobernabilidad y democracia son los principales viaductos a través de los cuales filtran los miles de millones de dólares que desde Washington se envía a los partidos políticos, ONG, grupos juveniles y sociales que promueven sus intereses en el mundo.(GOLINGER, 2014) Disponível em: http://actualidad.rt.com/opinion/eva_golinger/view/143043-agresion-permanente-golpesuave-america-latina. Acesso em: 26/09/2015

${ }^{9}$ Disponível em: https://search.wikileaks.org/plusd/cables/06CARACAS3356_a.html
} 
Desde que assumiu, em 2002, Chávez fortaleceu as instituições democráticas, criando mecanismos de representação e organização popular, promoveu reformas na Constituição Nacional, buscando otimizar e aumentar a participação da população nos assuntos públicos, e garantiu a liberdade de imprensa e a livre organização política (mesmo contra aqueles que incentivaram e apoiaram o golpe de 2002). No que tange a organização da sociedade civil, Chávez promoveu a criação das "Missões", dos conselhos comunais ${ }^{10}$ e criou Ministérios com o intuito de organizar e interligar ações de vários movimentos socais, tais como o movimento feminista e o camponês. O próprio fracasso do golpe militar de 2002 foi devido à organização da sociedade venezuelana que não aceitou a quebra da institucionalidade e se mobilizou para exigir o retorno de Chávez à presidência.

Assim, diante da exposição desses fatos, fica evidente qual a definição de sociedade civil foi adotada pelos EUA, ou seja, apenas a da oposição à Chávez.

É importante também que a definição de democracia seja situada, já que as acusações de que Chávez atenta contra os valores democráticos são costumeiras, em especial na grande mídia venezuelana (e também brasileira) ${ }^{11}$. No entanto, como acusar de antidemocrático um governo que foi eleito democraticamente, sendo que as eleições venezuelanas foram auditadas por instituições internacionais, como o Centro Carter? Como já foi apontado, na Constituição Bolivariana são previstos uma série de mecanismos que visam aumentar a participação popular, sendo que o próprio referendo revocatório convocado pela oposição, em 2004, é uma ferramenta constitucional. Portanto, para os EUA e a oposição, a democracia política, é válida apenas quando estes comandam o Estado, caso contrário, as mesmas regras e valores passam a ser entendidas como negativas e identificadas como autoritárias e/ou populistas.

10 Estas organizações constituem um modelo de "micro-governos" em pequenos espaços territoriais geográficos, cujos "governantes" pertencem à comunidade em causa. Fazem ainda parte de um projecto governamental mais amplo, que pretende reconstruir administrativamente o território, com base na criação de Comunas (ZUBER,Inês. Os "Conselhos Comunais" em Caracas, Venezuela. Reflexão acerca das similitudes e descoincidências com o conceito de "movimento social" IN: Revista Convergência Crítica Núcleo de Estudos e Pesquisas em Teoria Social - NEPETS, 2012.)

${ }^{11}$ Ver: SALGADO, Tiago. A Folha de S.Paulo e o governo Chávez (2002-2005). Dissertação de Mestrado, PUC-SP. 2013. 


\section{Os EUA e a oposição venezuelana}

O documento também lista uma série de instituições que receberam incentivos financeiros e jurídicos por parte dos EUA, estas são voltadas para a defesa dos Direitos Humanos e vinculadas à USAID/OIT, mas também a outras instituições, como a Freedom House $(\mathrm{FH})^{12}$. Chama a atenção, além do aporte financeiro ${ }^{13}$ dado para a oposição, o caráter "pedagógico" assumido pelos EUA em relação à Venezuela, pois, para o embaixador Brownfield, é necessário treinar e educar a "sociedade civil venezuelana".

FH provides training and technical assistance to 15 different smaller and regional human rights organizations on how to research, document, and present cases in situations of judicial impunity through a specialized software and proven techniques. ${ }^{14}$

É constante a utilização da expressão "sociedade civil” para fazer referência à oposição venezuelana, sendo esta uma prática comum não apenas no documento em questão, mas também no discurso de vários veículos de mídia e da própria oposição.

Para os EUA, a sociedade civil venezuelana se resume àqueles que são contrários ao governo Chávez, sendo que, portanto, todos os venezuelanos que votaram em Chávez não podem ser considerados membros de tal sociedade. Dessa forma, cria-se uma contradição, pois, se a sociedade civil é composta apenas de uma parcela minoritária da população, onde a maioria dos venezuelanos pode ser encaixada? Assim, a embaixada dos EUA acaba por deslegitimar a eleição de Chávez, uma vez que naturaliza e restringe a definição de sociedade civil como sendo limitada a apenas uma parcela da sociedade venezuelana. Dessa forma, mesmo defendendo um discurso legalista, a afirmação do

\footnotetext{
12 Segundo o historiador e cientista político Alberto de Vianna Moniz Bandeira, "Washington há muito tempo está a criar ONGs com o fito de promover demonstrações empreendidas, com recursos canalizados através da USAID, National Endowment for Democracy (NED) e CIA; Open Society Foundation (OSF), do bilionário George Soros, Freedom House, International Republican Institute (IRI), sob a direção do senador John McCain, etc.” Disponível em: http://cartamaior.com.br/?/Editoria/Politica/Moniz-BandeiraEUA-promovem-desestabilizacao-na-America-Latina-/4/33088. Acesso em:26/09/2015

13 "Sólo en Venezuela, invirtieron más de 100 millones de dólares en ése tiempo para alimentar a los grupos de la oposición, promoviendo adicionalmente la creación de más de 300 nuevas organizaciones no gubernamentales (ONG) y programas para filtrar y canalizar el dinero." (GOLINGER, 2014). Disponível em: http://actualidad.rt.com/opinion/eva_golinger/view/143043-agresion-permanente-golpe-suave-americalatina. Acesso em: 29/09/2015

${ }^{14}$ Disponível em: https://search.wikileaks.org/plusd/cables/06CARACAS3356_a.html
} 
documento vai de encontro à Constituição Bolivariana e, inclusive, contra a sua própria fundamentação, que se assenta na manutenção de bases legais para desestabilizar o governo chavista, pois, segundo a Carta Magna do país, todos os cidadãos e cidadãs têm o direito de participar livremente dos

[...] assuntos públicos, diretamente ou por meio de seus representantes eleitos ou eleitas. A participação do povo na formação, execução e controle da gestão pública é meio necessário para lograr o protagonismo que garanta seu completo desenvolvimento, tanto individual como coletivo. É obrigação do Estado e dever da sociedade facilitar a geração das condições mais favoráveis para sua prática. (Constituição da República Bolivariana da Venezuela apud SEABRA, 2012, p. 122).

Uma vez que o documento definiu quais setores fazem parte da sociedade civil na Venezuela, é clara a preocupação por parte dos EUA com o treinamento jurídico da oposição, sendo que existe, em especial após as tentativas golpistas frustradas de 2002, a necessidade de que a oposição conseguisse organizar, de forma legal, pressupostos que inviabilizassem o governo Chávez. Para tal, os EUA estariam dispostos a realizar a organização de eventos, congressos e encontros entre especialistas em direito de vários países que teriam a tarefa de instruir a oposição venezuelana.

Another key Chavez strategy is his attempt to divide and polarize Venezuelan society using rhetoric of hate and violence. OTI supports local NGOs who work in Chavista strongholds and with Chavista leaders, using those spaces to counter this rhetoric and promote alliances through working together on issues of importance to the entire community. OTI has directly reached approximately 238,000 adults through over 3000 forums, workshops and training sessions delivering alternative values and providing opportunities for opposition activists to interact with hard-core Chavistas, with the desired effect of pulling them slowly away from Chavismo. We have supported this initiative with 50 grants totaling over $\$ 1.1$ million. ${ }^{15}$

O documento também acusa o governo de distribuir nas escolas um material didático ideológico, com a intenção de popularizar um vocabulário revolucionário entre os jovens venezuelanos. Para os EUA, essa iniciativa é nociva, pois não respeita

\footnotetext{
${ }^{15}$ Disponível em: https://search.wikileaks.org/plusd/cables/06CARACAS3356_a.html
} 
pressupostos tidos como democráticos, entre eles, "respeito e tolerância política", sendo que a OIT trabalha com um programa educacional chamado "Democracy among us", cujo objetivo:

This interactive education program works through NGOs in low income communities to deliver five modules: 1) Separation of Powers, 2) Rule of Law, 3) The Role and Responsibility of Citizens, 4) Political Tolerance, and 5) The Role of Civil Society. ${ }^{16}$

Assim, de acordo com os objetivos desse programa, o "Democracy among us" tem a missão de passar, por meio de ações dentro das escolas venezuelanas, a importância dos pressupostos da democracia liberal e, assim, consequentemente, impedir que os valores da Revolução Bolivariana e da democracia participativa sejam colocados em práticas. Dessa forma, a operação ideológica proposta pela embaixada dos EUA visa naturalizar a democracia liberal como única alternativa política para a Venezuela, além de buscar apoio nos jovens, uma vez que estudantes são atores sociais tidos como autônomos e dificultam a ação das forças de segurança em caso de protestos violentos, já que muitas vezes são menores de idade.

Outro programa similar citado no documento é o "Por la Caracas possible", cujo intuito é recuperar a "once-beautiful Caracas", que nos últimos anos decaiu em função da corrupção e da falta de atenção das autoridades locais. Segundo o documento, o programa tem trabalhado com comunidades para "shining a light on the derrible job elected leadership are doing resolving the problem in Caracas", relatando ainda que foram expulsos de comunidades por líderes chavistas, o que "infuriating comunities that have already feel um-assisted".

É notório o esforço do documento em questão em demonstrar a preocupação estadunidense com a população venezuelana, mesmo que a "defesa de interesses econômicos vitais dos EUA" esteja presente entre os objetivos da Embaixada e do plano de desestabilização do governo Chávez. Assim, como foi possível perceber na avaliação do embaixador sobre a cidade de Caracas, é constante no documento a crítica a quadros eleitos do chavismo. No que tange a limpeza das ruas das cidades que formam a região da

\footnotetext{
${ }^{16}$ Disponível em: https://search.wikileaks.org/plusd/cables/06CARACAS3356_a.html
} 
grande Caracas, o documento afirma que "Due to incompetence of the local elected leadership, the garbage problem in Catia is a messy issue for all those who live there". Ao apontar a incompetência dos representantes eleitos, acaba-se por retirar a importância de um dos pressupostos mais defendidos pela oposição venezuelana e pelos EUA, o fato de que estes foram eleitos democraticamente, ou seja, que existe, de fato, uma democracia na Venezuela.

Também chama a atenção o fato de os EUA acusarem o governo Chávez de não respeitar a tolerância política dentro do país, sendo que o primeiro país a apoiar o golpe de 2002 - que vitimou centenas de venezuelanos e quebrou a institucionalidade legal foram os próprios estadunidenses, que também trabalharam, como mostra claramente o documento, para desestabilizar um governo democraticamente eleito, além de reduzir a sociedade civil àqueles que são contrários ao governo.

Sobre a questão dos Diretos Humanos, ao acusar o governo venezuelano de não respeitá-los, o documento acaba por, mais uma vez, demonstrar uma contradição em seu próprio discurso, pois a Constituição venezuelana trouxe avanços importantes, sendo que:

A nova Constituição nacional também contém claros avanços em relação aos Direitos Humanos, pois passou a incorporar os direitos indígenas e ambientais; reafirma o controle do Estado sobre as riquezas energéticas e estratégicas; garante aos militares o direito de voto; reduz a jornada de trabalho de 48 para 44 horas semanais; garante a indenização do trabalhador quando o empresário romper o contrato de trabalho; incorpora donas de casa e trabalhadores da economia informal ao sistema de seguridade social e confere o direito à saúde, educação e aposentadoria como deveres do Estado (SEABRA, 2012, p. 122).

Outro fator importante é o adjetivo utilizado para caracterizar a cidade de Caracas antes de Chávez. A capital venezuelana é definida como "a antes bela Caracas", que sucumbiu à incompetência de seus gestores chavistas. No entanto, no período em que os EUA consideram Caracas uma bela cidade, a Venezuela enfrentava sérios problemas econômicos e sociais: a guerrilha venezuelana era massacrada com aporte estadunidense, as políticas neoliberais que destruíam as condições de vida dos trabalhadores venezuelanos eram impostas pelos tradicionais partidos políticos, os lucros advindos do petróleo ficavam concentrados nas mãos das multinacionais e existiam poucos canais de 
participação popular, diferentemente do que acontece a partir das reformas propostas por Chávez e seu governo bolivariano. Dessa forma, para os EUA, é melhor uma "bela cidade" do que uma política pública mais justa e que melhorou a condição de vida dos trabalhadores venezuelanos, além é claro, de ignorar as mudanças e melhorias que ocorreram na cidade durante a administração chavista ${ }^{17}$.

Além de incentivar programas sociais de embelezamento das cidades venezuelanas e de defesa dos direitos humanos, o embaixador dos EUA visitou áreas pobres em diversos locais da Venezuela para "demonstratate US concern for the Venezuelan people", com o objetivo de rejeitar o discurso de Chávez de que os EUA são os grandes inimigos da Revolução Bolivariana.

Finally, through support of a positive social impact campaign in cooperation with PAS, OTI funded 54 social projects all over the country, at over \$1.2 million, allowing Ambassador to visit poor areas of Venezuela and demonstrate US concern for the Venezuelan people. This program fosters confusion within the Bolivarian ranks, and pushes back at the attempt of Chavez to use the United States as a "unifying enemy. ${ }^{18}$

Apesar de o documento mostrar a preocupação em negar que os EUA sejam inimigos da Venezuela chavista, sendo um defensor do fortalecimento das instituições democráticas, é possível perceber a intenção de desestabilizar o governo Chávez por meio de práticas tidas como legalistas, ou seja, os EUA proporcionaram, no período em questão, uma série de treinamentos para instituições opositoras ao governo bolivariano com o intuito de fornecer um arcabouço jurídico para derrubada de um governo democraticamente eleito. A intenção é "providing information internationally regarding the true revolutionary state of affairs", para assim, isolar a Venezuela no cenário internacional.

\footnotetext{
${ }^{17}$ Como exemplo podemos citar a existência de centros de cultura nas cidades venezuelanas, em especial as "Librerias del Sur", onde se encontram diversos livros subsidiados pelo governo a preços acessíveis. Os títulos variam de biografias de personagens históricos, como Simón Bolívar, a romances de autores venezuelanos e latino-americanos, e visam universalizar o acesso à cultura na Venezuela. (SALGADO,2013,p.141)

${ }^{18}$ Disponível em: https://search.wikileaks.org/plusd/cables/06CARACAS3356_a.html
} 
Segundo o documento, a FH e a OTI proporcionaram uma série de visitas por parte de opositores do governo a organizações apoiadas pelos EUA no México, no Chile, no Peru, na Argentina e, até mesmo, em Washington, com a intenção de educar os venezuelanos sobre a situação dos Direitos Humanos na Venezuela. Os EUA também patrocinaram a visita de uma série de "líderes internacionais" para conhecer melhor a situação venezuelana e advogar em defesa da oposição ao governo Chávez.

\begin{abstract}
Also, DAI has brought dozens of international leaders to Venezuela, university professors, NGO members, and political leaders to participate in workshops and seminars, who then return to their countries with a better understanding of the Venezuelan reality and as stronger advocates for the Venezuelan opposition.
\end{abstract}

Assim, a intenção de desestabilizar o governo Chávez é clara. No entanto, se nas décadas de 1960, 1970 e 1980 os EUA patrocinaram e apoiaram uma série de golpes militares na América Latina, no século XXI a intenção é derrubar o governo chavista de forma legal, ou seja, promover um "golpe legal” na Venezuela. É possível notar, durante a leitura de todo o documento, como a preocupação com as normativas legais são fundamentais para que a oposição venezuelana se fortaleça, sendo necessário encontrar brechas legais e apoio institucional para interromper o governo bolivariano.

A estratégia é aproveitar as contradições domésticas do país, os problemas internos, a fim de agravá-los, gerar turbulência e caos até derrubar o governo sem recorrer a golpes militares. (BANDEIRA, $2015)^{19}$

Para tal, os EUA apoiaram a mobilização de uma série de instituições e ONGs com o intuito de pressionar o governo venezuelano a partir de questionamentos acerca da Constituição do país, sendo que a Organização dos Estados Americanos (OEA ou OAS, em inglês) foi a principal instituição responsável por treinar os oposicionistas venezuelanos no que diz respeito às acusações contrárias ao governo Chávez.

19 Disponível em: http://cartamaior.com.br/?/Editoria/Politica/Moniz-Bandeira-EUA-promovemdesestabilizacao-na-America-Latina-/4/33088. Acesso em: 26/09/2015 
The Human Right Commission of the OAS has made several public statements and sent private latters to the National Assembly expressing concern with the law. [...] A private meeting between 4 Venezuelan human rights defenders and Secretary General Jose Miguel Inzulsa during October 2006 Inter-American Commision on Human Rights. ${ }^{20}$

A preocupação dos EUA com a situação dos Direitos Humanos na Venezuela, no entanto, é seletiva, uma vez que apenas o governo é acusado de violações. Os atos violentos da oposição que levaram, inclusive, a uma série de mortos - em episódios como o golpe de 2002 -, não são sequer mencionados, sendo que a imprensa, tanto a venezuelana como a internacional, é vista pelos EUA como um agente importante para divulgar a situação venezuelana e gerar um isolamento de Chávez no cenário internacional. Dessa forma, o documento ignora o fato de que a imprensa venezuelana foi a principal articuladora do golpe contra Chávez em 2002.

En abril de 2002, la administración de George W. Bush apoyó un golpe de Estado contra el Presidente Chávez, dirigido por la misma élite que había estado en el poder antes en Venezuela . El golpe de Estado utilizó marchas masivas en las calles de Caracas, integradas por la clase media y la clase alta, pidiendo el derrocamiento de Chávez. Utilizaron francotiradores para disparar a la gente en las marchas, creando violencia y caos, y luego responsabilizando a Chávez por la masacre8. La televisión, radio y los periódicos en Venezuela se unieron a los esfuerzos de golpe de Estado, manipulando las imágenes y distorsionando los hechos para justificar al derrocamiento del Presidente (GOLINGER,2014) ${ }^{21}$.

Na realidade, o que se pode observar é que a posição dos meios de comunicação venezuelanos - em relação ao governo - assumiu uma dimensão de destaque enquanto expressão dos embates pelo domínio do poder político e da influência sobre as verbas disponíveis no orçamento estatal, sendo que as acusações ao governo tornaram-se mais acirradas frente às medidas do presidente Hugo Chávez, que considerou ser necessário não apenas atuar no sentido de minimizar as diferenças sociais, mas também em divulgar para a população o que realmente acontecia no país. Nesse sentido, incentivou a criação

\footnotetext{
${ }^{20}$ Disponível em: https://search.wikileaks.org/plusd/cables/06CARACAS3356_a.html

${ }^{21}$ Disponível em: http://actualidad.rt.com/opinion/eva_golinger/view/143043-agresion-permanente-golpesuave-america-latina. Acesso em:26/09/2015
} 
de canais estatais como o "canal internacional Telesur" (MARINGONI, 2009, p. 155), que começou a transmitir no ano de 2005 com uma "vocación social orientado a liderar y promover los procesos de unión de los pueblos del SUR" e

[...] ser un multimedio y multiplataforma de servicio público con cobertura global que, desde el SUR, produce y divulga contenido informativo y formativo para una base de usuarios amplia y leal; con una visión integradora de los pueblos ${ }^{22}$.

Outra iniciativa do governo venezuelano que atingiu os meios de comunicação foi a elaboração da "Lei de Responsabilidade Social em Rádio e Televisão”, propondo: “[...] disciplinar cotas de programas locais em todas [as] emissoras, a veiculação de anúncios e regulamentar a defesa daqueles que tenham sido expostos injustamente pelos meios de comunicação" (MARINGONI, 2009, p. 156).

Assim, configura-se uma tentativa por parte do governo dos EUA de promover um "golpe legal” na Venezuela, estratégia essa, que segundo Eva Golinger, teve início em 1983 e consiste na criação de fundações "semi-privadas" como a National Endowment for Democracy (NED), o Instituto Republicano Internacional (IRI), o Instituto Democrata Nacional (NDI) e Freedom House que são utilizadas pelo governo dos EUA para oferecer auxílio jurídico e financeiro para partidos políticos e organizações sociais que promoviam uma agenda pró EUA em países que se afastavam dos interesses de Washington (GOLINGER,2014)

Dessa forma, por meio da construção de um discurso aparentemente em defesa da democracia e dos Direitos Humanos, os EUA, com apoio de diversos atores sociais que atuam na Venezuela, inclusive a imprensa e organizações políticas, buscou deslegitimar um governo democraticamente eleito por meio de uma construção discursiva legalista, que esconde os reais interesses estadunidenses na Venezuela e na América Latina, que é, como o próprio documento diz, "protecting vital US business".

${ }^{22}$ Informações obtidas no site do canal Telesur: http://www.telesurtv.net/el-canal, acesso em 05/06/2015. 


\section{Referências Bibliográficas:}

BANDEIRA, Moniz. Moniz Bandeira: "EUA promovem desestabilização na América Latina". Disponível em: http://cartamaior.com.br/?/Editoria/Politica/Moniz-BandeiraEUA-promovem-desestabilizacao-na-America-Latina-/4/33088

COLMENARES, Elio. La inssurección de febrero. Una análisis para la lucha revolucionaria. Caracas, Ediciones La Chipa, 1989.

GOLINGER, EVA. Una Agresión Permanente: El Golpe Suave en América Latina (Parte 1). Disponível em: http://actualidad.rt.com/opinion/eva_golinger/view/143043agresion-permanente-golpe-suave-america-latina MARINGONi (DE OLIVEIRA), Gilberto. A Revolução Venezuelana. 1. ed. São Paulo: Editora UNESP, 2009. (Revoluções do Século 20)

SEABRA, Raphael Lana. A Primeira Revolução do Século XXI? Bolivarianismo e Socialismo na Venezuela. 2012. 234f. Tese (Doutoramento em Sociologia) - Instituto de Ciências Sociais - ICS, Universidade de Brasília - UnB, Brasília/DF.

SALGADO, Tiago. A Folha de S. Paulo e o governo Chávez (2002-2005). Editora Paco. Jundiaí, São Paulo - 2015.

ZUBER, Inês. Os “Conselhos Comunais” em Caracas, Venezuela. Reflexão acerca das similitudes e descoincidências com o conceito de "movimento social" IN: Revista Convergência Crítica Núcleo de Estudos e Pesquisas em Teoria Social - NEPETS, 2012.

\section{Documentação}

Doc Number: 13376 . SECRET - USAID/OTI PROGRAMMATIC SUPPORT FOR COUNTRY TEAM 5 POINT STRATEGY. SECRET. Disponível em: https://search.wikileaks.org/plusd/cables/06CARACAS3356_a.html 